\title{
CONHECIMENTO DAS LEIS DE TRÂNSITO POR VÍTIMAS DE ATROPELAMENTO, EM BELO HORIZONTE, EM 1997
}

\author{
KNOWLEDGE OF TRAFFIC LAW BY VICTIMS OF ACCIDENTS IN BELO HORIZONTE, IN 1997
}

Walter J. Fagundes-Pereira ${ }^{1}$; Raquel Tanure ${ }^{2} \&$ Andy Petroianu $^{3}$

\begin{abstract}
'Médico Residente de Neurocirurgia do Hospital Universitário Santa Casa de Belo Horizonte. ${ }^{2}$ Médica. ${ }^{3}$ Docente do Departamento de Cirurgia da Faculdade de Medicina da UFMG; Docente livre da Escola Paulista de Medicina - UNIFESP e da Faculdade de Medicina de Ribeirão Preto - USP.

Correspondência: Walter J. F. Pereira - Rua Nossa Senhora da Conceição, 402 - CEP: 31.130-240 - Belo Horizonte, MG Fone: (031) 442.3831 - E-mail: walterjf@nlet.em.com
\end{abstract}

FAGUNDES-PEREIRA WJ; TANURE R \& PETROIANU A. Conhecimento das leis de trânsito por vítimas de atropelamento, em Belo Horizonte, em 1997. Medicina, Ribeirão Preto, 32: 189-192, abr./jun. 1999.

RESUMO: Em nosso país, os acidentes no trânsito são uma das principais causas de invalidez e morte, particularmente entre os jovens. Realizou-se o presente estudo, visando a averiguar o conhecimento que os atropelados têm a respeito das leis de trânsito. Foram estudadas cem vítimas de atropelamento, atendidas no Pronto Socorro do Hospital João XXIII, em Belo Horizonte, em 1997. Dos entrevistados, sessenta e sete (67) eram homens e trinta e três (33) eram mulheres, com idades variando entre dezoito (18) e oitenta (80) $(M=36,8 \pm 17,2)$ anos. Somente sete pacientes tinham habilitação para dirigir automóveis; outros dezessete (17) conheciam a legislação de trânsito e tinham noção de direção. Portanto, $76 \%$ das vítimas desconheciam as leis de trânsito. Acreditamos que talvez seja lícito supor que pessoas que não têm conhecimento das leis de trânsito possam estar mais susceptíveis a serem vítimas de acidentes. A falta de noções básicas sobre as normas de trânsito poderia favorecer o aumento do número de atropelamentos.

UNITERMOS: Acidentes de Trânsito; Condução de Veículo.

\section{INTRODUÇÃO}

A rápida urbanização e a predominância do transporte rodoviário, além da valorização social do automóvel provocaram em nosso país um grande crescimento no número de veículos, sem uma infra-estrutura correspondente que pudesse absorver tal desenvolvimento e, principalmente, sem a conscientização do risco dos veículos automotores para a população. A frota brasileira que, em 1960, era de 508.608 veículos, saltou para 6.227.672 em 1975 e triplicou em 1990 para 18.267.245. Estima-se que, em 1997, haja mais de trinta milhões de veículos em circulação e que, em 2008, serão 55.084.891 ${ }^{(1)}$. Atualmente, quarenta milhões de pessoas possuem carteira de habilitação para condução de veículos no Brasil ${ }^{(2)}$.
Os acidentes no trânsito são uma das principais causas de invalidez e morte, particularmente entre os jovens, o que se traduz em diminuição da população potencialmente ativa e eleva o custo da saúde públi$\mathrm{ca}^{(3)}$. Segundo Lima (1998), o Estado brasileiro tem prejuízo de, pelo menos, dez bilhões de dólares por ano com os acidentes de trânsito, no que se refere a gastos com tratamento das vítimas, com a Previdência Social e com o investimento do governo no cidadão que morre prematuramente no trânsito ${ }^{(1)}$. Em 1980, eles constituíram a sétima causa de morte; já, em 1985, tornaram-se a quinta causa.

Atualmente, cerca de 3,5\% de todas as mortes ocorridas no Brasil são por acidentes de trânsito. Esse percentual é muito alto se comparado com os 2,2\% dos Estados Unidos e 1,1\% da Holanda ${ }^{(1)}$. Em 1960, o 
número de mortos em acidentes de trânsito foi de 3.785; em 1997, estima-se ser mais de 28.000, dos quais onze mil por atropelamento ${ }^{(2)}$. Tudo isso faz do Brasil destaque, no cenário mundial, em violência no trânsito.

Em Belo Horizonte, cidade com mais de três milhões de habitantes e uma frota de 814.179 veículos, predomina a morte por acidentes de trânsito na faixa etária de cinco (05) a quarenta e cinco (45) $\operatorname{anos}^{(2)}$. Dados da Secretaria de Segurança Pública do Estado de Minas Gerais, de 1995, mostram que houve 10.791 vítimas de acidentes automobilísticos, em Belo Horizonte, sendo 5.007 deles pedestres. As vítimas fatais perfizeram um total de 386 pedestres (Tabela I). Esses dados se traduzem em 5,2 mortes para cada dez mil veículos ${ }^{(1)}$. Essa situação não parece ser diferente em outras capitais, como Curitiba ${ }^{(3)}$, Porto Alegre $^{(4)}$ e Brasília ${ }^{(5)}$.

\begin{tabular}{|c|c|c|}
\hline Idade & Masculino & Feminino \\
\hline$<5$ anos & 160 & $99(7)$ \\
\hline $5-14$ & $715 \quad(3,8)$ & $384(1,3)$ \\
\hline $15-24$ & $681 \quad(5,6)$ & $425 \quad$ (3) \\
\hline $25-34$ & $557 \quad(11,1)$ & $309 \quad(7,7)$ \\
\hline $35-59$ & $700 \quad(12,5)$ & $458 \quad(9,6)$ \\
\hline$>60 a$ & $277 \quad(18,8)$ & $242(7,8)$ \\
\hline Total & 2270 & 1917 \\
\hline
\end{tabular}

Tendo em vista a escassez de literatura referente a acidentes de trânsito e, em particular, a atropelamentos e suas vítimas em nosso meio, foi realizado o presente estudo, visando a averiguar o nível de conhecimento que os atropelados têm sobre as leis de trânsito.

\section{CASUÍSTICA E MÉTODO}

Foram estudadas cem vítimas de atropelamento, atendidas no Setor de Pronto Socorro do Hospital João XXIII, em Belo Horizonte, em 1997. Os pacientes foram identificados por sexo, idade, cor e profissão. Todos foram entrevistados com vista ao nível de escolaridade e se tinham habilitação para dirigir veículo automotivo. Investigou-se ainda a categoria do veículo envolvido no acidente e as condições em que este ocorreu. As vítimas de atropelamento que não sabiam dirigir foram questionadas sobre os conhecimentos das normas básicas do trânsito de veículos (placas de sinalização, preferência de trânsito de veículos e pedestres, faixa de travessia de pedestres, sinais luminosos, etc.). Todos os pacientes eram maiores de dezoito (18) anos e apresentavam-se conscientes à entrevista. Caso contrário eram excluídos do estudo.

Os resultados foram comparados pelo teste qui quadrado e as diferenças foram consideradas significativas, quando maiores do que as correspondentes a $\mathrm{p}=0.05$. Utilizou-se a correção de Yates, quando a freqüência esperada foi inferior a dez.

\section{RESULTADOS}

Foram avaliados sessenta e sete (67) homens e trinta e três (33) mulheres, com as idades variando entre dezoito (18) e oitenta (80) $(\mathrm{M}=36,8 \pm 7,2)$ anos, sendo que $41 \%$ tinha de dezoito (18) a vinte e nove (29) anos, 35\%, de trinta (30) a quarenta e nove (49) anos, $19 \%$ de cinqüenta (50) a sessenta e nove (69) anos e apenas 5\% tinham setenta (70) anos ou mais. De acordo com a cor da pele, trinta e seis (36) eram leucodérmicos, quarenta e um (41) eram feodérmicos e vinte e três (23) eram melanodérmicos. Se for considerada a proporção de cores da pele na população do Estado de Minas Gerais (leucodérmicos - 57\%, feodérmicos - $35 \%$ e melanodérmicos - $8 \%$ ) bem como a do geral de pacientes atendidos no mesmo hospital (leucodérmicos - 13\%, feodérmicos - $85 \%$ e melanodérmicos - $2 \%$ ), observa-se que existe uma significativa predominância de melanodérmicos atropelados ( $\mathrm{p}<0,01)$.

Em relação à escolaridade dos pacientes, dezessete (17) eram analfabetos, vinte e sete (27) tinham nível primário, quarenta e sete (47) primeiro grau completo; oito, o segundo grau completo; e apenas um possuía curso superior. A maioria dos pacientes pertenciam à classe social baixa. Em relação à profissão, dezessete (17) eram donas-de-casa; onze (11), pedreiros; oito (08), aposentados; quatro (04), estudantes; e três (03), lavradores.

Somente sete pacientes tinham habilitação para dirigir automóveis, e outros dezessete (17) conheciam a legislação de trânsito e sabiam dirigir veículos. Os demais, $76 \%$, das vítimas, negaram conhecimento das leis de trânsito. Nesta casuística, as pacientes do sexo feminino não possuíam habilitação e somente uma tinha conhecimento das leis de trânsito (Tabela II). 
Tabela II - Distribuição das vítimas de atropelamentos que sabiam ou não conduzir veículos e que tinham ou não carteira de habilitação de acordo com o sexo, em Belo Horizonte, em 1997

\begin{tabular}{|lcccccc|}
\hline Condutores & Masculino & Sim & Feminino & Masculino & Feminino & Total \\
\hline Conhece leis de trânsito & 16 & $1^{*}$ & 51 & $32^{*}$ & 100 \\
\hline Habilitado & 7 & - & 60 & 33 & 100 \\
\hline
\end{tabular}

$\left({ }^{*}\right) p<0,05$

Em relação à categoria dos veículos envolvidos nos atropelamentos, predominaram carros $(62 \%)$, seguidos por ônibus (13\%), caminhão (9\%), moto (8\%) e bicicleta $(6 \%)$.

\section{DISCUSSÃO}

Os dados obtidos no presente estudo sugerem que a falta de noções básicas sobre as normas de trânsito relacionou-se com os atropelamentos. Segundo dados do Departamento de Trânsito de Minas Gerais (DETRAN-MG), a maior parte dos atropelamentos deve-se a infrações cometidas pelos pedestres. Atravessar fora da faixa de pedestre, desrespeito às placas de sinalização e aos semáforos e falta de orientação quanto ao sentido do fluxo de veículos são as principais causas de atropelamento por culpa dos pedestres. Não se deve, entretanto, isentar o motorista de culpa, pois sua desatenção, aliada à imprudência, negligência, e até imperícia, contribui, de forma decisiva, para que o acidente ocorra.

Percebe-se pelas Tabelas I e II que, apesar de Belo Horizonte contar com mais mulheres do que homens, as vítimas masculinas predominaram. Acreditamos ser pertinente supor que o comportamento social mais agressivo e menos cuidadoso por parte dos homens esteja na origem desses acidentes. Mesmo conhecendo as leis de trânsito e sabendo dirigir, vários homens, acidentados, desrespeitaram as normas básicas de travessia das ruas. Quanto às mulheres atropeladas, nenhuma conhecia a legislação de trânsito e também foram vítima de sua imprudência ao atravessar a rua.

Tanto em relação à população do estado quanto à população hospitalar, houve uma predominância de negros, o que pode eventualmente estar relacionado com a classe social dos pacientes atendidos no hospital.

As estatísticas de trânsito mostram números cada vez mais alarmantes. É certo que projetos devam ser elaborados, visando a reduzir tais índices e, conseqüentemente, diminuir as taxas de invalidez e mortalidade. Deve-se ressaltar que a prevalência de adultos jovens, nos atropelamentos, repercute de forma importante sobre a população ativa. Portanto, campanhas educativas sobre as normas de trânsito, orientação de pedestres e motoristas e conscientização da população sobre os perigos provocados pelos automóveis, devem ser implementadas, de forma mais agressiva. Talvez elas devam dar prioridade aos homens, que parecem ser os principais causadores e vítimas de tais acidentes, por seu comportamento mais imprudente.

A legislação ultrapassada e desrespeitada por toda a população, incluindo as autoridades "competentes", que não punem as infrações, pode ser considerada como uma das principais causas da realidade catastrófica e vergonhosa do trânsito em nosso país. Não se deve atribuir, como querem algumas pessoas, que, seja um problema de civilização ou tradição cultural, pois o nosso povo é, sem dúvida, tão civilizado quanto as populações de países considerados mais avançados. Sabemos que o problema, na verdade, está na impunidade das infrações que contribuem para deixar o cidadão mais desprotegido. Assim, a implantação do novo Código Nacional de Trânsito ${ }^{(6,7,8,9)}$, inspirado na legislação de países mais desenvolvidos, através de punições severas para os infratores, parece ser a mais séria tentativa para transformar o motorista brasileiro em um ser educado, respeitador e menos perigoso $^{(6)}$, modificando a impressão causada ao escritor francês Albert Camus, em 1960, que disse: "o motorista brasileiro ou é um alegre louco ou um frio sádico". Faz-se necessário afastar a assustadora estimativa do Swedish Road and Traffic Research Institute, do governo sueco, que, durante a vida, metade de todas as crianças que nascerem no primeiro ano do século XXI vão sofrer acidentes de trânsito ${ }^{(3)}$.

Concluindo, o presente trabalho sugere que a falta de conhecimento das normas básicas do tráfico de veículos pelos pedestres pode ser um dos fatores a contribuir para o aumento do número de atropelamentos. Campanhas que atinjam toda a população de pedestres, com vista a sua educação nas leis de trânsito, talvez possam reduzir o número de atropelamentos. 
FAGUNDES-PEREIRA WJ; TANURE R \& PETROIANU A. Knowledge of traffic law by victims of accidents in Belo Horizonte, in 1997. Medicina, Ribeirão Preto, 32: 189-192, apr./june 1999.

ABSTRACT: Traffic accidents are one of the great causes of disability and of death mainly in young people of our country. The present study assessed the knowledge of traffic laws of one hundred victims of accidents 67 men and 33 women, in Belo Horizonte, in 1997. Their ages ranged between 18 and $80(M=36,817,2)$ years old. Only seven of them had drive license and only, other 17 had knowledge about the traffic laws. So $76 \%$ of victims do not have knowledge about the traffic laws. We believe that it is worth to suppose people who do not know about traffic laws may be more susceptible to car accidents. The lack of knowledge on basic traffic laws may contribute increasing the amount of accidents.

UNITERMS: Accidents, Traffic. Automobile Driving.

\section{REFERÊNCIAS BIBLIOGRÁFICAS}

1 - PINTO LC. Trânsito matou mais de 660 mil em 37 anos. J Folha São Paulo, p. 1-7, 18.01.98.

2 - BARCELOS H. Trânsito: o desfio do século. J Casa, p.3, 28.09.97.

3 - SOBANIA LC; TATESUJI BS \& PACHECO CES. Acidentes de tráfego, um problema de saúde pública. Rev Bras Ortop 24: 13-22, 1989.

4 - FISHMANN A; AGUIAR CRS \& MINOTTO R. Estudo descritivo sobre atropelamento no trânsito de Porto Alegre. Rev HPS 36: 12-15, 1990.

5 - BRITO EM; COSTA GR;ALVES RS; MENEZES EA; DUARTE SC. Vítimas de traumatismo crânio-encefálico em vítimas de acidentes de trânsito atendidas no Hospital de Base do Distrito Federal em 1994 e 1995. Rev Saúde Dist Fed 7: 41-49, 1996.
6 - VARELLA F \& MEZAROBBA G. A força da lei contra a selvageria. Rev Veja, p. 64-69, 21.01.98.

7 - DEPARTAMENTO NACIONAL DE TRÂNSITO. Campanha nacional do novo Código de Transito Brasileiro. J Estado Minas. p. 13, 25.01.98.

8 - DAMÉ L. O novo Código de Trânsito. J Folha São Paulo, p. $9,15.01 .98$.

9 - GARCIA R. O novo Código de Trânsito. J Estado Minas, p. $15,15.01 .98$.

Recebido para publicação em 01/04/98

Aprovado para publicação em 01/06/99 